05,13

\title{
Спин-волновой резонанс в одномерных магнонных кристаллах, на примере мультислойных пленок Со-P
}

\author{
(ㄱ Р.С. Исхаков ${ }^{1}$, С.В. Столяр ${ }^{2}$, Л.А. Чеканова ${ }^{1}$, И.Г. Важенина ${ }^{1, \uparrow}$ \\ ${ }^{1}$ Институт фозики им. Л.В. Киренского СО РАН - обособленное подразделение ФИЦ КНЦ СО РАН, \\ Красноярск, Россия \\ ${ }^{2}$ Федеральный исследовательский центр „Красноярский научный центр \\ Сибирского отделения Российской академии наук“, \\ Красноярск, Россия \\ ฯ E-mail: irina-vazhenina@mail.ru
}

Поступила в Редакцию 28 мая 2020 г.

В окончательной редакции 28 мая 2020 г.

Принята к публикации 28 мая 2020 г.

Методом спин-волнового резонанса были исследованы слоистые магнитные пленки Со-Р-сплава, представляющие собой набор ламинатов, где каждый ламинат имеет определенную атомную и химическую структуру. Синтезированные покрытия двух видов: магнонный кристалл (аморфный $\mathrm{Co}(\mathrm{P}) / \Gamma Ц К ~ \mathrm{Co}(\mathrm{P}))_{\mathrm{N}}$ и градиентные пленки $\mathrm{Co}(\mathrm{P})$, позволили наблюдать две различные модификации спектра СВР. В одном случае спектр СВР $H_{n}(n) \sim n^{2}$ с модификацией, обусловленной образованием первой стоп-зоны магнонного кристалла. Во втором, зависимость резонансных полей $H_{n}$ спин-волновых мод от номера моды $n$ имеет вид $H_{n}(n) \sim n^{2 / 3}$. Термоотжиг приводит к кристаллизации $(\mathrm{AC} \rightarrow$ ГЦК) и вызывает трансформацию слоистых пленок в пленки однофазных Со-Р-сплавов, что отражается в изменении формы спектров СВР и регистрации модификации спектра вида „обменный излом“.

Ключевые слова: спин-волновой резонанс, константа поверхностной анизотропии, константа обменного взаимодействия, аморфные и нанокристаллические сплавы.

DOI: 10.21883/FTT.2020.10.49915.115

\section{1. Введение}

Спектр волн в периодических структурах имеет зонный характер с запрещенными и разрешенными значениями энергии. Внутри каждой разрешенной энергетической зоны дисперсионное выражение для спиновых волн описывается квадратичной зависимостью $\omega \sim k^{2}$. Как известно, закон дисперсии спиновых волн в ферромагнетике $\omega \sim k^{2}$, поэтому в спектре спин-волнового резонанса (CВР) ферромагнитных пленок позиции резонансных полей стоячих обменных спиновых волн $H_{n}$ от номера моды $n$ имеют дискретный вид: $H_{n} \sim n^{2}$ [1-3]. Частное решение уравнения намагниченности для ферромагнитных пленок является гармонической функцией [4]. Границы зон, если экспериментальный диапазон волновых векторов в магнонных кристаллах охватывает сразу несколько разрешенных энергетических зон, проявляются на регистрируемых спектрах спин-волнового резонанса в виде дуплета моды с волновым вектором $k_{\text {critic }}[5,6]$.

Работы первых десятилетий, после открытия явления CВР в тонких магнитных пленках $[1,3]$, в основном были посвящены исследованию однородных тонких пленок $(100-400 \mathrm{~nm})$ с квадратичной зависимостью $H_{n}(n)$. Так как измерения зависимости $H_{n} \sim n^{2}$ позволяли сравнительно просто определять величину обменной жесткости спиновых волн. Однако в это же время на ферромагнитных пленках экспериментально наблюдались неквадратичные зависимости $H_{n}(n)$ и был опубликован ряд теоре- тических работ [7-11], направленных на интерпретацию экспериментальных результатов [11-16]. Оказалось, что можно выделить два механизма, которые приводят к отклонениям от квадратичного закона. Первый приводит к отклонениям от $H_{n} \sim n^{2}$ в узкой волновой области вокруг характерного волнового вектора $k_{C}$ и связан со случайным распределением магнитных параметров (обмен, намагниченность) по объему пленки, и, в случае доминирования какого-либо одного магнитного параметра, оказалось возможным по виду модификации экспериментального спектра СВР установить не только тип этого параметра, но и ряд статистических характеристик (среднее значение магнитного параметра и его дисперсию, корреляционный радиус $r_{C} \approx 1 / k_{C}$ ) [9-11]. Второй механизм, вызывающий модификацию спектров СВР во всем волновом диапазоне, обусловлен преобладанием распределения магнитного параметра, описываемого определенной функциональной зависимостью по толщине пленки, над случайными флуктуациями. Так, Портис [7] предположил параболическое изменение намагниченности по толщине пленки и объяснил экспериментально наблюдаемое Кооі [12] линейное соотношение $H_{n}(n)$ для пленок FeNi. Шлюманн [8] интерпретировал эксперименты Nisenoff and Terhune [13] на пленках пермаллоя, исходя из линейного изменения эффективного поля по толщине пленки, что позволило получить теоретическую зависимость резонансных полей от номера моды вида $H_{n} \sim n^{2 / 3}$, соответствующую экспериментальной. 


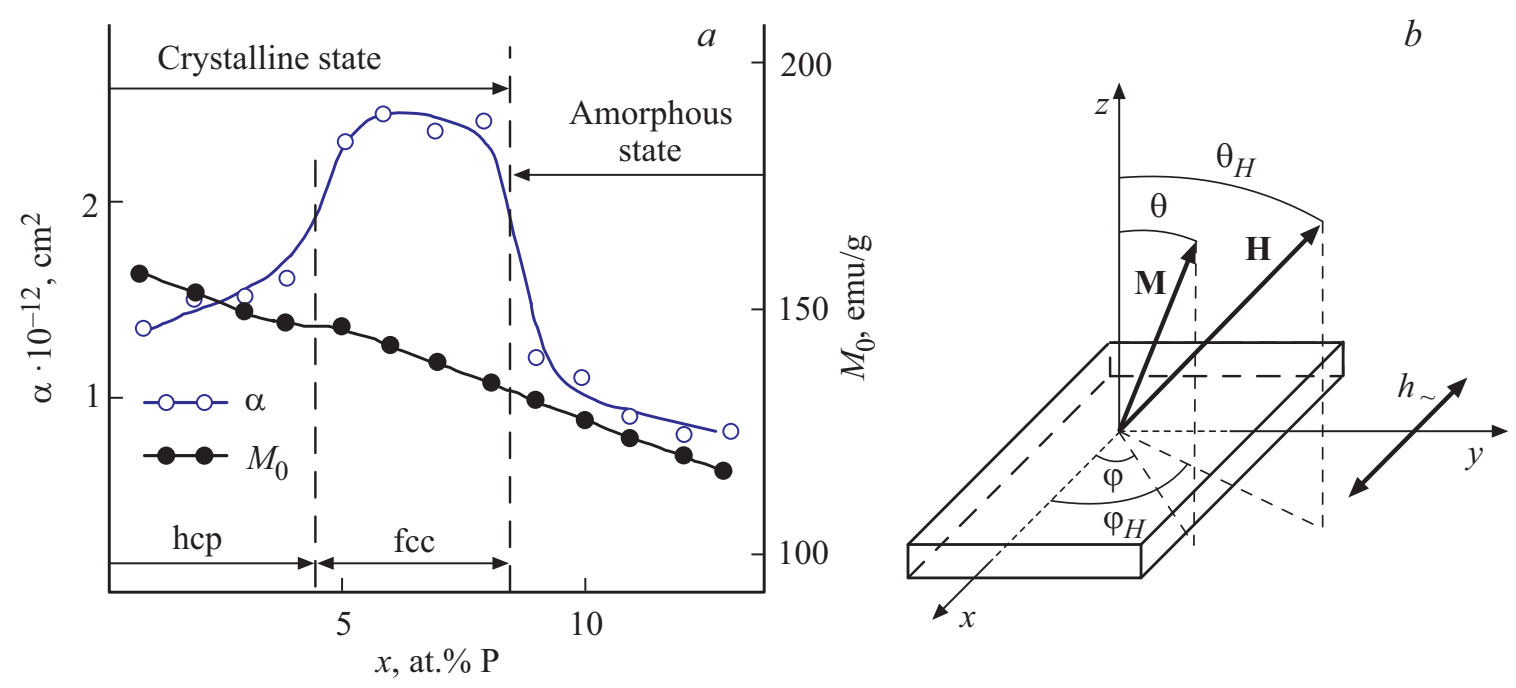

Рис. 1. Концентрационные зависимости обменной константы и намагниченности насыщения в сплавах Со-P $(a)[37]$ и геометрия проведения эксперимента $(b)$.

В последние годы было выполнено значительное количество экспериментальных работ [17-20], посвященных исследованию механизмов, приводящих в спектре СВР к зависимостям вида $H_{n} \sim n$ и $H_{n} \sim n^{2 / 3}$. Отличительной чертой указанных исследований можно отметить использование однослойной пленки, в которой осуществить контроль по пространственному распределению магнитных параметров по толщине пленки весьма сложно, что часто приводит к отличным друг от друга результатам для одинаковых систем $[21,22]$.

Поэтому для исследований особенностей СВЧ-спектров все чаще выбирается вариант ламинатной (мультислойной) пленки, которая позволяет сформировать требуемую атомную, химическую и магнитную структуру ферромагнитной пленки. Примерами успешности подобного подхода являются работы [5,6,23-28], в которых изучался спектр спиновых волн в магнонном кристалле и в эффективной среде. Оказалось, что метод спин-волнового резонанса позволяет идентифицировать изменения не только магнитных, но и структурных параметров ферромагнитной системы [29-34]. Последнее обусловлено тем обстоятельством, что метод СВР позволяет определить такие фундаментальные параметры спиновой системы как константа обменного взаимодействия $A$, эффективная намагниченность $M_{e f f}$ и константа анизотропии $K$, а они в свою очередь, зависят от атомной и химической структуры материала.

Целью настоящей работы было исследование, на примере мультислойных пленок $\mathrm{Co}(\mathrm{P})$, композиционно модулированных структур с заданным распределением изменения структуры от нанокристаллической к аморфной, позволившие получить пленки двух видов: одномерный магнонный кристалл и градиентная структура. Заложенные модуляции позволили на СВЧ-спектрах методом СВР регистрировать два типа модификации спектра обменных спиновых волн - один из которых обусловлен первой стоп-зоной магнонного кристалла, а второй характеризуется распределением резонансных полей вида $H_{n} \sim n^{2 / 3}$.

\section{2. Образцы и методы исследования}

Исследуемые в работе слоистые (ламинатные) пленки Со-Р-сплавов были синтезированы методом химического осаждения из растворов солей соответствующих металлов. Ранее в большом количестве работ $[32,33,35,36]$ было изучено влияние содержания фосфора как на атомную структуру Сo-P-сплавов, так и на магнитные характеристики пленок Со-Р-сплавов, обусловленные атомной и химической структурой в них. Результаты, проведенных исследований однослойных пленок, позволяют говорить о влиянии содержания $\mathrm{P}$ в сплаве $\mathrm{Co}-\mathrm{P}$ на изменение фазового состояния сплава (атомные решетки ГПУ, ГЦК и аморфная структура). Указанные структурные превращения влияют на основные фундаментальные магнитные характеристики (обмен, намагниченность, анизотропия) и особенно ярко проявляются на концентрационной зависимости константы обменного взаимодействия в диапазоне 0-10 at.\% Р (рис. 1,a).

Были синтезированы две серии слоистых пленок, отличающиеся друг от друга формируемым концентрационным профилем по толщине пленки. Образцы первой серии представляют собой ламинатные структуры с чередующимися слоями аморфного (90 at.\% Со и 10 at.\% P) и нанокристаллического (93 at.\% Сo и 7 at.\% $\mathrm{P}$ ) Со-Р-сплава, что позволило сформировать периодический ступенчатый профиль изменения концентрации фосфора по толщине образца (рис. 2,a). Таким образом, многослойные пленки $\left[\mathrm{Co}_{90}^{\text {am }} \mathrm{P}_{10}\left(d_{1}\right) / \mathrm{Co}_{93}^{\text {crystal }} \mathrm{P}_{7}\left(d_{2}\right)\right]_{7}$ являются периодически модулированными по всем магнитным параметрам структурами, т.е. магнонным кристаллом: следовательно их спектр должен иметь зонный 

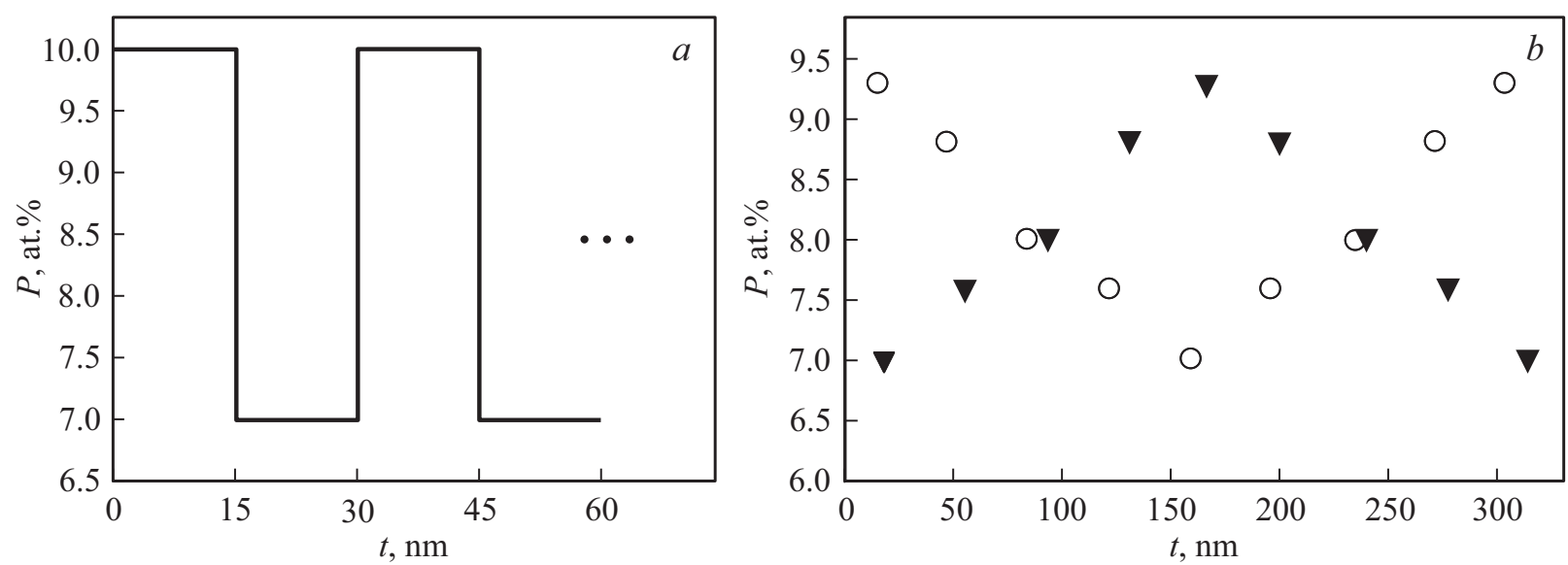

Рис. 2. Ступенчатый профиль при манипуляции содержания фосфора $(a)$ и зависимость распределения фосфора по толщине градиентной пленки $(b)$.

характер с разрешенными и запрещенными значениями энергий для спиновых волн. Края зон Бриллюэна определяются волновыми векторами $k_{\text {critic }}=\pi\left(d_{1}+d_{2}\right)^{-1}$, диапазон значений которых для первой и второй разрешенной зоны, был соотнесен с диапазоном значений измеряемых волновых векторов. Подбор толщин индивидуальных слоев $\left(d_{1}=d_{2}=15 \mathrm{~nm}\right.$, где $d_{1}+d_{2}-$ период одномерной модуляции) и числа повторений пар $(N=7)$ в синтезируемых образцах позволил сформировать первую и вторую зону Бриллюэна с границей на 7 моде, так что величина запрещенной щели в полевых координатах описывается дублетом мод СВР при $n=7$.

Вторая серия также представлена слоистыми пленками того же сплава, но изменение содержания фосфора по толщине покрытия было подобрано таким образом, чтобы реализовывалась линейная функция по концентрации at.\% Р. В этом случае переход от аморфного к нанокристаллическому состоянию (или наоборот) (рис. 2,b) делит пленку Со-P сплава на три области по толщине: аморфная-наноГЦК-аморфная, либо наноГЦК-аморфная-наноГЦК. Толщина индивидуальных слоев в градиентных пленках варьировалась в диапазоне от 30 до $35 \mathrm{~nm}$, количество слоев - 9. Следует отметить, что сформированная подобным образом химическая структура может рассматриваться как масштабированная граница между аморфным и кристаллическим слоями (рис. 2,a), что позволяет исследовать эффекты, происходящие на интерфейсе между слоями $\left(d_{1}\right.$ и $\left.d_{2}\right)$.

Измерение спектров ФМР и СВР пленок при комнатной температуре было выполнено на стандартном спектрометре ЭПА-2М с частотой накачки $9.2 \mathrm{GHz}$. Динамические характеристики измерялись как при параллельно приложенном внешнем магнитном поле $\left(\theta_{H}=90^{\circ}\right)$, так и когда оно ориентировано нормально относительно поверхности $\left(\theta_{H}=0^{\circ}\right)$ (рис. $\left.1, b\right)$. Кривые СВЧ-поглощения, имеющие сложную форму (рис. 3), были разложены на составляющие с помощью дифференцированной функции Лоренца, выбор которой учитывал отсутствие вклада электрической компоненты (обусловлено конструкцией резонатора и размерами образца).

\section{3. Результаты и обсуждение}

Известно, что при определенных граничных условиях $[1,38]$, в тонкой однородной ферромагнитной пленке под воздействием постоянного Н и однородного переменного $\mathbf{h}_{\sim}$ магнитных полей могут возбуждаться стоячие обменные спиновые волны. Позиции резонансных полей $H_{n}$, когда внешнее магнитное поле Н приложено ортогонально к плоскости пенки $\left(\mathbf{H} \perp \mathbf{h}_{\sim}\right)$, описываются выражением

$$
H_{n}=\frac{\omega}{\gamma}+4 \pi M_{e f f}-\frac{2 A}{M_{S}} k^{2},
$$

где $\gamma=1.758 \cdot 10^{7} \mathrm{~Hz} / \mathrm{Oe}-$ гиромагнитное соотношение, $\omega-$ фиксированная частота микроволнового поля, $M_{e f f}$ - эффективная намагниченность, $A-$ константа обменного взаимодействия, представляемая выражением $A=2 J S^{2} / a$ и связанная с обменной жесткостью $\eta$ $\left(\eta=2 A / M_{S}\right) ; k-$ волновой вектор $(k=n \pi / d$, где $n-$ порядок моды, $d$ - толщина пленки). Зависимость $H_{n}$ от $n^{2}$ можно построить, имея экспериментальную кривую СВР и проводя идентификацию $n$ по некоторым правилам, хорошо изложенным в $[2,39]$. Возможность применения соотношения (1) для описания стоячих спиновых волн в мультислойных пленках была показана в работах $[6,31,40-44]$.

Положение резонансных полей стоячих обменных спиновых волн (в неоднородной среде с флуктуирующими магнитными параметрами) в нанокристаллических и аморфных пленках описываются выражением

$$
H_{n}=\frac{\omega}{\gamma}+4 \pi \cdot M_{e f f}-\langle\eta\rangle k^{2}\left(1-\gamma_{i}^{2} J_{i}(k)\right),
$$

где функция $J_{i}(k)$ описывает влияние флуктуаций, проявляющихся в отклонениях (изломах) зависимости 
Магнитные параметры пленок до и после отжига

\begin{tabular}{|c|c|c|c|c|c|}
\hline & $\begin{array}{c}M_{e f f}, \\
\mathrm{G}\end{array}$ & $\begin{array}{c}A \cdot 10^{-6} \\
\mathrm{erg} / \mathrm{cm}\end{array}$ & $\begin{array}{c}\left|K_{S 1}\right| \\
\mathrm{erg} / \mathrm{cm}^{2}\end{array}$ & $\begin{array}{c}\left|K_{S 2}\right| \\
\mathrm{erg} / \mathrm{cm}^{2}\end{array}$ & $\begin{array}{l}r_{C}, \\
\mathrm{~nm}\end{array}$ \\
\hline \multicolumn{6}{|c|}{ До отжига } \\
\hline$\left[\mathrm{Co}^{a m}(15 \mathrm{~nm}) / \mathrm{Co}^{\text {crystal }}(15 \mathrm{~nm})\right]_{7}$ & 1366 & $\sim 0.95$ & $\sim 0.67$ & $\sim 0.32$ & \\
\hline \multicolumn{6}{|c|}{ После отжига } \\
\hline$\left[\mathrm{Co}^{a m}(15 \mathrm{~nm}) / \mathrm{Co}^{\text {crystal }}(15 \mathrm{~nm})\right]_{7}$ & 1372 & $\sim 0.65$ & $\sim 0.39$ & $\sim 0.17$ & $\sim 26$ \\
\hline Градиентная пленка $\left[\mathrm{Cox} \mathrm{Py}_{\mathrm{N}}\right.$ & 1274 & $\sim 0.378$ & $\sim 0.22$ & $\sim 0.16$ & $\sim 22$ \\
\hline
\end{tabular}

$H_{n}\left(n^{2}\right)$ от прямой линии при характерном волновом векторе $k^{*}=1 / r_{C}$ [9-11], $\gamma_{i}^{2}-$ величина среднеквадратиченой флуктуации спинового параметра. Среди возможных модификаций закона дисперсии, которые описывает (2), для анализа результатов данной работы следует выделить флуктуации обмена („обменный“ излом), наличие которых можно идентифицировать по изменению тангенса угла наклона зависимости $H_{n}\left(n^{2}\right)$ с большего значения на меньшее. Так, регистрируемые спектры СВР реперных однослойных пленок Сo-P, как наноГЦК, так и аморфных, описывались нестандартным киттелевским соотношением $H_{n} \sim n^{2}$, с обменным изломом в области $k \sim k_{C}$.

В случае наличия в магнитной структуре пленки линейного изменения эффективного поля [8], аналитическое выражение связи положений резонансных полей $H_{n}$ и номера моды, имеет вид

$$
H_{n}=H_{0}-\left(\frac{2 A}{M}\right)^{1 / 3} \cdot\left[\frac{3 \pi}{2}\left(n+\frac{1}{4}\right)\right]^{2 / 3} \cdot\left(\frac{H_{\text {grad }}}{d}\right)^{2 / 3},
$$

где $H_{0}$ - эффективное поле однородной прецессии намагниченности, $H_{\text {grad }}$ - величина, характеризующая градиент магнитного поля по толщине образца.

Случайные (естественные) и искусственно созданные неоднородности в тонких пленках особенно наглядно проявляются в виде характерных особенностей на зависимости обменной жесткости $\eta^{e f f}(n)$, которая описывается выражением

$$
\eta^{e f f}=\frac{H_{1}-H_{j}}{n_{j}^{2}-1} \cdot\left(\frac{d}{\pi}\right)^{2} .
$$

Особенность $\eta^{e f f}(n)$, в случае реализации квазизоны Бриллюэна, заключается в уменьшении величины $\eta$ для волн при $k \leq k_{\text {critic }}$, скачка величины $\eta$ при $k=k_{\text {critic }}$, и последующего уменьшения $\eta$ до среднего значения обменной жесткости $\langle\eta\rangle$ для волн с $k \geq k_{\text {critic }}$. Величина критического волнового вектора выражается соотношением

$$
k_{\text {critic }}=\frac{n \pi}{N\left(d_{1}+d_{2}\right)},
$$

в котором количество бислоев $N$ равно номеру моды $n$.
Флуктуации обмена характеризуются уменьшением величины $\eta^{e f f}(n)$ в области $k_{C}^{*}[9-11,45,46]$.

Экспериментальные спектры слоистых пленок $\left[\mathrm{Co}_{90}^{a m} \mathrm{P}_{10}(15 \mathrm{~nm}) / \mathrm{Co}_{93}^{\text {crystal }} \mathrm{P}_{7}(15 \mathrm{~nm})\right]_{7}$, с описанными особенностями - до отжига в спектре реализуется дуплет на 7 моде (энергетическая щель между первой и второй зоной Бриллюэна), после кристаллизующего аморфный сплав отжига: „обменный“ излом - представлены на рис. 3, $a$ и $c$. Структура всех регистрируемых спектров имеет ряд особенностей. Во-первых, наличие поверхностных мод (на рис. 3 обозначены $S 1$ и $S 2$ ) свидетельствует об антисимметричном закреплении поверхностных спинов, когда трудная ось поверхностной анизотропии нормальна к поверхности пленки (константа поверхностной анизотропии $\left.K_{S}<0\right)$ [47]. Созданные граничные условия приводят к реализации в спектрах четных мод с интенсивностью существенно меньшей, чем интенсивность соседних нечетных мод. Заданные условия синтеза - количество слоев и их толщины, позволяют наблюдать образование дуплета седьмой моды, который в полевых координатах обозначивает края запрещенной зоны спектра спиновых волн. Моды с номерами п равными 1, 3, 4, 5 и 7 характеризуют первую квазизону Бриллюэна, ко второй квазизоне относятся моды с номерами 7, 9 и 11. Стоит отметить, что в пределах каждой зоны положение резонансных полей от номера моды описывается выражением (1) (рис. 4,a). Ширина запрещенной зоны $\Delta H_{B}$ в полевых координатах, равная разнице между значениями резонансных полей седьмых мод, составляет $\sim 500$ Ое. Авторы работы [5] также наблюдали проявление в спектре СВР границ запрещенных зон на структурах из сплава Со-Р, но смежные слои имели нанокристаллическую структуру (ГПУ Со/ГЦК Со). Ширина запрещенных зон в таком магнонном кристалле согласно их измерениям составила $\sim 200$ Ое. Полученные данные могут свидетельствовать, что разница в величине $\Delta H_{B}$ может быть обусловлена не только различием в типе флуктуирующего параметра (см. [5]), но и отличием в атомной структуре чередующихся слоев.

Представленная на рис. 3, $a$ идентификация номеров спин-волновых мод и выражение (4) позволили определить величины эффективной спин-волновой жестко- 

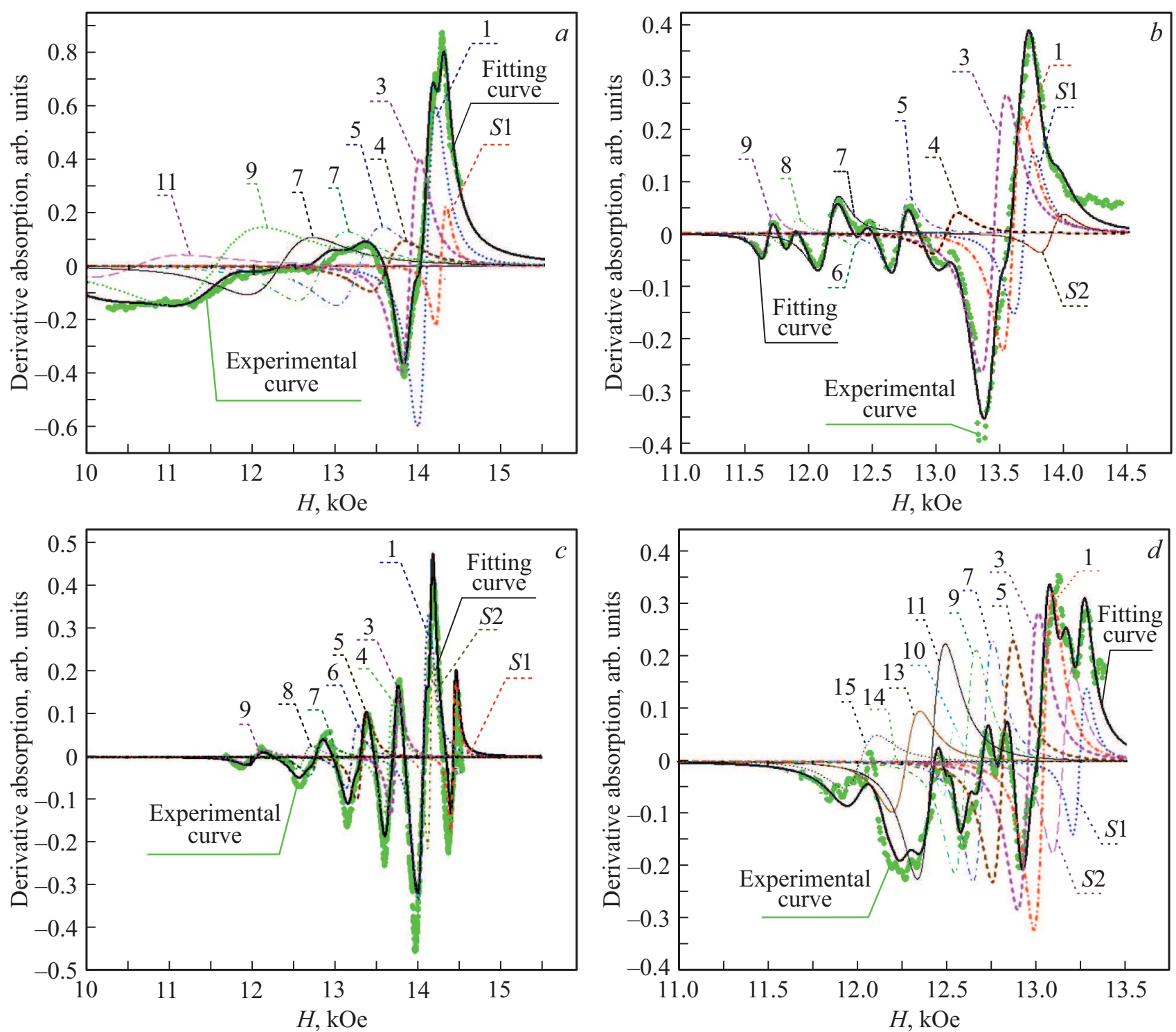

Рис. 3. Спектры СВР до отжига ( $a$ и $b)$ и после отжига ( $c$ и $d)$ для слоистой пленки $\left[\mathrm{Co}_{90}^{a m} \mathrm{P}_{10}(15 \mathrm{~nm}) / \mathrm{Co}_{93}^{c r y s t a l} \mathrm{P}_{7}(15 \mathrm{~nm})\right]_{7}(a$ и $c)$ и градиентной пленки $[\mathrm{Cox} \mathrm{Py}]_{\mathrm{N}}(b$ и $d)$.

сти $\eta^{e f f}$, зависимости которой от номера моды демонстрируется на вставке рис. 4, $a$. Наличие двух отдельных ветвей в зависимости $\eta^{e f f}(n)$ (рис. 4,a) с границей на 7 моде хорошо согласуется с описанными ранее особенностями и величиной $k_{\text {critic }}$, определенной из (5).

Таким образом, в одномерном периодическом магнонном кристалле, изготовленном в виде мультислойной пленки с модуляцией структуры „нанокристаллический ферромагнетик/аморфный ферромагнетик“ в виде ступенчатой концентрационной функции, зарегистрирован спектр СВР; его обработкой определена модификация спектра спиновых волн, обусловленная образованием первой и второй зон Бриллюэна магнонного кристалла.

Необходимо отметить, что по технологическим причинам (метод химического осаждения) граница между слоями не является атомарно резкой - величина интер- фейса составляет 1-2 nm. Однако подбором соотношений между периодом модуляции и регистрируемыми величинами волновых векторов можно по модификациям спектра СВР, разделить вклады от периодичности слоев и вызванные влиянием интерфейса.

Эффекты, обусловленные интерфейсом, исследовались на градиентной пленке с линейным профилем изменения концентрации фосфора по толщине пленки. Экспериментальный спектр СВР градиентной пленки представлен на рис. $3, b$. Положения резонансных полей от номера моды с высокой степенью точности совпадают с зависимостью вида $\left(H_{1}-H_{n}\right) \sim n^{2 / 3}$ (рис. $\left.4, b\right)$.

Кристаллизационный (аморфное состояние $\rightarrow$ ГЦК) отжиг как периодического магнонного кристалла, так и градиентной пленки, привел к формированию макроскопически однородной пленки Сo-P-сплава с флукту- 

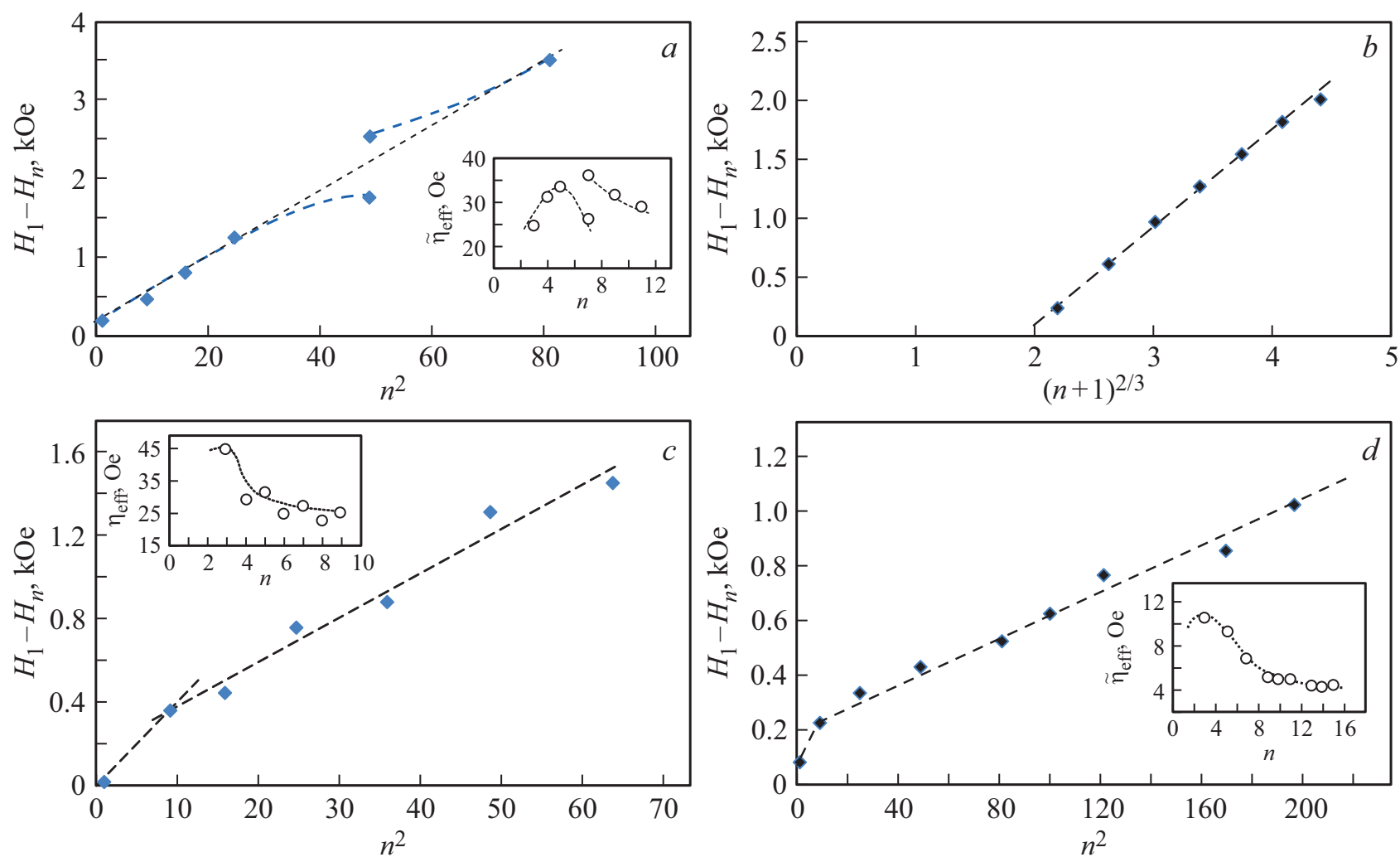

Рис. 4. Зависимость положения резонансного поля $H_{i}$ от номера моды $n$ до отжига $(a$ и $b)$ и после отжига $(c$ и $d)$ для слоистой пленки $(a$ и $c)$ и градиентной пленки $\left[\mathrm{Cox}_{\mathrm{x}}\right]_{\mathrm{N}}(b$ и $d)$. На вставках показаны зависимости эффективной обменной жесткости от номера моды.

ациями на наномасштабе. Таким образом, одномерная периодическая (апериодическая) модуляция композиционной структуры заменяется на изотропные флуктуации магнитного параметра.

Экспериментальные кривые спектров СВР после термоотжига представлены на рис. 3,c и $d$. Зависимость положений резонансных полей от квадрата номера моды (рис. 4,c и $d$ ) демонстрируют модификацию спектра СВР, вызванную доминирующим характером в случайных флуктуациях магнитных параметров системы константы обменного взаимодействия $[11,15,16,46]$. Вид зависимости $\eta^{e f f}(n)$ для каждого образца после отжига (вставка к рис. 4, $c$ и $d$ ) также подтверждает доминирующую роль неоднородности обменного параметра. Значения эффективной намагниченности $M_{e f f}$, константы обменного взаимодействия $A$, константы поверхностной анизотропии $K_{S}$ были вычислены на квадратичных участках зависимости $H_{n}\left(n^{2}\right)$ с использованием (1), по значению волнового вектора $k^{*}$ в точке излома был определен масштаб неоднородности (корреляционный радиус $r_{C}$ ) обмена (см. таблицу).

\section{4. Заключение}

Таким образом, в мультислойных пленках „нанокристаллический ферромагнетик/аморфный ферромагнетик“
(ГЦК $\mathrm{Co}(\mathrm{P}) / \mathrm{AC} \operatorname{Co}(\mathrm{P}))$ и слоистых пленках с градиентной химической структурой, методом СВР экспериментально обнаружены модификации спектра стоячих спиновых обменных волн, обусловленные как образованием первой и второй зоны Бриллюэна (магнонный кристалл Со-Р при равенстве критического волнового вектора $k_{C}$ волновому вектору границы зоны Бриллюэна $k_{B}$ ), так и формируемым линейным профилем внутреннего эффективного поля: $H_{n} \sim n^{2 / 3}$. Также установлено, что кристаллизационный $(\mathrm{AC} \rightarrow$ ГЦК $\mathrm{Co}(\mathrm{P}))$ термоотжи слоистых пленок Со-P приводит к трансформации в структуру неупорядоченного ГЦК твердого раствора с практически изотропной неоднородной спиновой системой, что проявляется в соответствующих модификациях закона дисперсии обменных спиновых волн. Полученные результаты позволяют сделать предположение о достаточно сильном влиянии различий в типе структуры смежных слоев (ГЦК-ГПУ или ГЦК-аморфное состояние) на магнитные параметры системы - на энергетическую щель между первой и второй зоной Бриллюэна в полевых координатах $\Delta H_{B}$ до отжига, и на корреляционный радиус $r_{C}$ после отжига.

\section{Конфликт интересов}

Авторы заявляют, что у них нет конфликта интересов. 


\section{Список литературы}

[1] C. Kittel. Phys. Rev. 110, 1295 (1958).

[2] Н.М. Саланский, М.Ш. Ерухимов. Физические свойства и применение магнитных пленок. Наука, Новосибирск. (1975). $221 \mathrm{c}$

[3] M.H. Seavey, P.E. Tannenwald. Phys. Rev. Lett. 1, 168 (1958).

[4] Л.Д. Ландау, Е.М. Лифшиц. К теории дисперсии магнитной проницаемости ферромагнитных тел. Наука, М. (1969) $128 \mathrm{c}$.

[5] Р.С. Исхаков, С.В. Столяр, Л.А. Чеканова, М.В. Чижик. ФTT 54, 704 (2012)

[6] Р.С. Исхаков, С.В. Столяр, М.В. Чижик, Л.А. Чеканова. Письма в ЖЭТФ 94, 325 (2011).

[7] A.M. Portis. Appl. Phys. Lett. 2, 69 (1963).

[8] E. Schlömann. J. Appl. Phys. 36, 1193 (1965).

[9] В.А. Игнатченко, Р.С. Исхаков. ЖЭТФ 72, 1005 (1977).

[10] В.А. Игнатченко, Р.С. Исхаков. ЖЭТФ 74, 1386 (1978).

[11] В.А. Игнатченко, Р.С. Исхаков, Л.А. Чеканова, Н.С. Чистяков. ЖЭТФ 75, 653 (1978).

[12] P.E. Wigen, C.F. Kooi, M.R. Shanabarger, U.K. Cummings, M.E. Baldwin. J. Appl. Phys. 34, 1137 (1963).

[13] M. Nisenoff, R.W. Terhune. J. Appl. Phys. 35, 806 (1964).

[14] Р.С. Исхаков, М.М. Бруштунов, Л.А. Чеканова. ФТТ 29, 2699 (1987).

[15] Р.С. Исхаков, М.М. Бруштунов, А.Г. Нармонев, И.А. Турпанов, Л.А. Чеканова. ФММ 79, 122 (1995).

[16] L.J. Maksymowicz, D. Sendorek-Temple, R. Żuberek. J. Magn. Magn. Mater. 58, 303 (1986).

[17] L. Dreher, C. Bihler, E. Peiner, A. Waag, W. Schoch, W. Limmer, S.T.B. Goennenwein, M.S. Brandt. Phys. Rev. B 87, 224422 (2013).

[18] B. Hoekstra, R.P. van Stapele, J.M. Robertson. J. Appl. Phys. 48, 382 (1977).

[19] А.И. Дмитриев, Р.Б. Моргунов, О.Л. Казакова, Й. Танимото. ЖЭТФ 135, 1134 (2009).

[20] X. Liu, J.K. Furdyna. J. Phys..Condens. Matter. 18, R245 (2006).

[21] S.T.B. Goennenwein, T. Graf, T. Wassner, M.S. Brandt, M. Stutzmann, J.B. Philipp, R. Gross, M. Krieger, K. Zürn, P. Ziemann, A. Koeder, S. Frank, W. Schoch, A. Waag. Appl. Phys. Lett. 82, 730 (2003).

[22] Y. Sasaki, X. Liu, T. Wojtowicz, J.K. Furdyna. J. Supercond. Nov. Magn. 16, 143 (2003).

[23] Р.С. Исхаков, Л.А. Чеканова, С.В. Столяр, И.Г. Важенина. Изв. РАН. Сер. физ. 78, 502 (2014).

[24] Р.С. Исхаков, Л.А. Чеканова, И.Г. Важенина. Изв. РАН. Сер. физ. 77, 1469 (2013).

[25] Е.Н. Каблов, О.Г. Оспенникова, В.П. Пискорский, Д.В. Королева, Ю.Е. Калинин, А.В. Ситников, Е.И. Куницын, А.Д. Таланцев, В.Л. Бердинский, Р.Б. Моргунов. ФТТ 58, 1086 (2016).

[26] S.A. Nikitov, P. Tailhades, C.S. Tsai. J. Magn. Magn. Mater. 236, 320 (2001).

[27] Y.V. Gulyaev, S.A. Nikitov. Dokl. Phys. 46, 687 (2001).

[28] В.В. Кругляк, А.Н. Кучко, В.И. Финохин. ФТТ 46, 842 (2004).

[29] V.A. Ignatchenko, Y.I. Mankov, A.A. Maradudin. Phys. Rev. B 62, 2181 (2000).

[30] В.А. Игнатченко, Ю.И. Маньков, Д.С. Цикалов. ЖЭТФ 134, 706 (2008).
[31] Р.С. Исхаков, Н.А. Шепета, С.В. Столяр, Л.А. Чеканова, В.Ю. Яковчук. Письма в ЖЭТФ 83, 31 (2006).

[32] Л.А. Чеканова, Р.С. Исхаков, Г.И. Фиш, Р.Г. Хлебопрос, Н.С. Чистяков. Письма в ЖЭТФ 20, 73 (1974).

[33] Л.А. Чеканова, Р.С. Исхаков, Г.И. Фиш, Р.Г. Хлебопрос, Н.С. Чистяков, Е.Н. Агартанова. ФММ 41, 536 (1976).

[34] Л.А. Чеканова, Р.С. Исхаков, Р.Г. Хлебопрос, Н.С. Чистяков, Г.И. Фиш. ФТТ 20, 3501 (1978).

[35] Р.С. Исхаков, А.С. Чеканов, Л.А. Чеканова. ФТТ 30, 970 (1988).

[36] В.Н. Бержанский, Л.А. Чеканова, Н.С. Чистяков. ФММ 46, 63 (1978).

[37] Р.С. Исхаков, А.С. Чеканов, Л.А. Чеканова. ФТТ 32, 441 (1990).

[38] W.S. Ament, G.T. Rado. Phys. Rev. 97, 1558 (1955).

[39] А.Г. Гуревич. Магнитный резонанс в ферритах и антиферомагнетиках. Наука, М. (1973). 591 с.

[40] R.P. van Stapele, F.J.A.M. Greidanus, J.W. Smits. J. Appl. Phys. 57, 1282 (1985).

[41] R. Kordecki, R. Meckenstock, J. Pelzl, H. Mühlbauer, G. Dumpich, S. Nikitov. J. Appl. Phys. 70, 6418 (1991).

[42] R. Kordecki, R. Meckenstock, J. Pelzl, S. Nikitov, J.C. Lodder. J. Magn. Magn. Mater. 121, 524 (1993).

[43] Р.С. Исхаков, Ж.М. Мороз, Л.А. Чеканова, Е.Е. Шалыгина, Н.А. Шепета. ФТТ 45, 846 (2003).

[44] Р.С. Исхаков, И.В. Гавришин, Л.А. Чеканова. Письма в ЖЭТФ 63, 938 (1996).

[45] В.А. Игнатченко, Р.С. Исхаков. Изв. АН СССР. Сер. физ. 44, 1434 (1980).

[46] Р.С. Исхаков, Д.Е. Прокофьев, Л.А. Чеканова, В.С. Жигалов. Письма в ЖТФ 27, 81 (2001).

[47] И.Г. Важенина, Р.С. Исхаков, Л.А. Чеканова. ФТТ 60, 287 (2018).

Редактор К.В. Емцев 